\title{
Rectal indomethacin reduces the risk of post-endoscopic retrograde cholangiopancreatography pancreatitis in low-risk patients
}

\author{
Mohamed M. Abdelfatah ${ }^{\mathrm{a}, \mathrm{b}}$, Eric Gochanourb, Nicholas J. Koutlas ${ }^{\mathrm{b}}$, Ahmed Hamed $^{\mathrm{b}}$, Glenn Harvin ${ }^{\mathrm{b}}$, \\ Mohamed O. Othmanc
}

University of Alabama at Birmingham, Alabama; East Carolina University, Greenville, North Carolina; Baylor College of Medicine, Houston, Texas, USA

\begin{abstract}
Background Evidence shows that rectal indomethacin (RI) reduces the risk of post-endoscopic retrograde cholangiopancreatography (ERCP) pancreatitis (PEP) in high-risk patients. The prophylactic role of RI in low-risk patients has not yet been identified. The objective of our study was to evaluate the impact of RI in preventing PEP in low-risk patients.

Methods A retrospective cohort study was conducted to evaluate the impact of RI in preventing PEP. RI was available starting November 2012. Patient characteristics and procedure details were collected.

Results The study population included 2238 patients who underwent ERCP (1055 in the RI group and 1183 in the control group). PEP was diagnosed in 107 patients (4.8\%). In a multivariate model of consecutive patients, RI reduced the incidence of PEP by $55 \%$ (odds ratio [OR] 0.45, 95\% confidence interval $[\mathrm{CI}]$ 0.36-0.94; $\mathrm{P}=0.03)$. In a multivariate model that included $1874(84 \%)$ low-risk patients, RI reduced the incidence of PEP by $62 \%$ (OR 0.38, 95\%CI 0.19-0.74; P=0.004). Propensity-matched group analysis was performed for low-risk native papilla patients. RI reduced the incidence of PEP by $61 \%$ (OR 0.39, 95\%CI 0.18-0.8; $\mathrm{P}=0.009$ ).

Conclusion RI reduced PEP in consecutive as well as low-risk patients. RI should be administrated in consecutive patients unless contraindicated. Larger prospective studies are needed to confirm our results.
\end{abstract}

Keywords Post-endoscopic retrograde cholangiopancreatography, rectal indomethacin, prophylactic pancreatic duct stents

Ann Gastroenterol 2020; 33 (4): 1-8

\section{Introduction}

Post-endoscopic retrograde cholangiopancreatography (ERCP) pancreatitis (PEP) is the most frequent major complication of ERCP. PEP occurs in 1-9\% of average-risk patients [1] and from $11-40 \%$ of high-risk patients, with a $0.1 \%$

Division of ${ }^{\mathrm{a}}$ Gastroenterology, Hepatology, and Nutrition, Department of Internal Medicine, University of Alabama at Birmingham, Alabama (Mohamed M. Abdelfatah); ' Gastroenterology, Hepatology, and Nutrition, Department of Internal Medicine, East Carolina University, Greenville, North Carolina (Mohamed M. Abdelfatah, Eric Gochanour, Nicholas J. Koutlas, Ahmed Hamed, Glenn Harvin); 'Gastroenterology and Hepatology, Baylor College of Medicine, Houston, Texas (Mohamed O. Othman), USA

\section{Conflict of Interest: None}

Correspondence to: Mohamed Abdelfatah Magdy, MD, Assistant professor, Division of Gastroenterology and Hepatology, University of Alabama at Birmingham, USA, e-mail: dr.mohamed.magdy@hotmail.com

Received 26 August 2019; accepted February 2020; published online 15 May 2020

DOI: https://doi.org/10.20524/aog.2020.0492 mortality risk related to pancreatitis and an annual healthcare expenditure totaling \$199 million in the United States [2-9].

Freeman et al showed that prophylactic pancreatic duct stents (PDS) could reduce the incidence of PEP from 23\% to $4 \%$ in high-risk patients [10]. Multiple studies have confirmed that PDS placement could effectively minimize pancreatitis in high-risk patients [11-19]. One meta-analysis reported an $88 \%$ success rate for PDS placement and a low complication rate (1.8\%). Moreover, placing a PDS reduced PEP from $15.5 \%$ to $5.8 \%$ (odds ratio $[\mathrm{OR}] 3.2,95 \%$ confidence interval [CI] 1.6-6.4) and reduced the incidence of severe PEP to $11.5 \%[15,20,21]$. The number needed to treat showed that PDS should be placed in 10 patients to prevent one episode of PEP [22].

Nevertheless, there has been inconsistent adoption of this technique among endoscopists [10], perhaps because PDS placement has an unacceptable failure rate, especially in patients with small and stenotic ducts [13,23]. It was noted that failure to successfully place a PDS could cause more harm than if PDS placement was not attempted [12,24]. Secondly, complications can be seen with PDS in up to $4.9 \%$ of patients, including misplacement, proximal migration and subsequent duct injury, and stricture that can lead to 
chronic pancreatitis $[16,25]$. Thirdly, PDS placement requires follow-up imaging and potentially repeat endoscopy to remove the retained stent, thus increasing costs.

Given the substantial burden from PEP, multiple pharmacological agents have been studied as prophylaxis against PEP. With the exception of rectal non-steroidal antiinflammatory drugs (NSAIDs), all other pharmacological prophylactic agents have shown disappointing results. A prospective controlled study conducted by Elmunzer et al reported a $46 \%$ relative risk reduction of PEP with rectally administered indomethacin (RI) compared to placebo alone in high-risk patients [26]. The study was criticized later because $80 \%$ of the patients with high suspicion for sphincter of Oddi dysfunction (SOD) had PDS placement, whereas lower-risk patients had indomethacin therapy [27] Two meta-analyses, including data from Elmunzer et al, have shown that rectal NSAIDs prevent PEP $[28,29]$. Shortly after these studies were published, the European Society for Gastrointestinal Endoscopy (ESGE), followed by the Japanese guideline, recommended RI in all patients undergoing ERCP without complications [30,31]. A retrospective study of 4017 patients by Thiruvengadam et al showed that RI reduced the risk of PEP in low-risk patients and patients with malignant obstruction [32].

In contrast, in a prospective randomized trial of a cohort where $70 \%$ of patients were at average risk for PEP, Levenick et al showed that RI does not prevent PEP in consecutive patients [33]. Two other randomized trials [34,35], followed by 2 meta-analyses by Inamdar and Feng et al concluded that RI does not prevent PEP in average-risk patients [36,37]. Further complicating the issue, Rainio et al published a retrospective study of 2000 consecutive patients, demonstrating that rectal diclofenac did not affect the incidence or severity of PEP [38]. Given the above evidence, the role of RI in consecutive patients is not clear. The current recommendation of the ASGE is RI should be given to high-risk patients and may be considered in average-risk patients [39].

Pharmacological agents could offer the ideal prophylaxis measures, preferable to PDS because of their safety profile and low cost. However, RI does not eliminate the risk of PEP in high-risk patients, and the role of RI in low-risk patients is still considered controversial. Furthermore, it is not known whether the combination of RI with PDS can offer additional benefit in decreasing the incidence and severity of PEP. Accordingly, the objective of our study was to evaluate the impact of RI in preventing PEP in consecutive patients and to determine whether the combination of RI and PDS decreases the incidence of PEP compared to RI alone.

\section{Patients and methods}

After approval by the University and Medical Center Institutional Review Board at East Carolina University/Vidant Medical Center, we conducted a retrospective study of all ERCPs performed at Vidant Medical Center from January 2007 to October 2016. ERCP procedures performed before January
2009 were excluded because electronic medical records were not used in our institution at that time. The study included all patients who underwent diagnostic or therapeutic ERCP from January 2009 to October 2016. RI was available starting in November 2012. The indomethacin group consisted of patients who received $100 \mathrm{mg}$ RI during or immediately after the ERCP while the unexposed group consisted of patients who did not receive RI.

The procedures were performed by 4 experienced endoscopists, no trainees were involved in any of the procedures. All patients underwent ERCP with a standard duodenoscope (TJF-160F and TJF-Q180V; Olympus Optical Co., Ltd., Tokyo, Japan). Patient characteristics and procedural details were collected. PEP was defined by consensus criteria. Patients noted to have had acute pancreatitis within $72 \mathrm{~h}$ before the procedure were excluded from the study.

Patients were observed in the recovery area for at least $2 \mathrm{~h}$ after the procedure and were assessed by the endoscopy nurse and the endoscopist before discharge. Patients who developed symptoms of PEP were monitored closely and received intravenous hydration after confirmation of the diagnosis.

We reviewed patients' demographic information, relevant medical history and home medications. Likewise, physician medication orders and nursing notes were reviewed to confirm that the patient received RI before or immediately after the ERCP. We reviewed available laboratory blood work, pre- and post-procedure imaging studies, and follow-up documentation. Procedural notes were reviewed with careful attention to diagnosis and indications for ERCP and the use of anesthesia or sedation. Procedural details were recorded, including sphincterotomy, biopsy, stent placement/removal, cannulation of the common bile duct or the main pancreatic duct, cholangiogram or pancreatogram. In addition to noting the type and size of the stent used, we also gathered information on other therapeutic interventions during the ERCP.

\section{Follow up}

We reviewed all the documented complications of ERCP in the electronic health record from subsequent admissions, emergency room or follow-up clinic visits, nurse phone calls post-procedure, and notifications of admissions to another hospital or emergency room. Complications including postERCP pancreatitis, pancreatic necrosis and death were collected.

\section{Definitions}

PEP was defined as new-onset or worsening abdominal pain causing an unplanned admission following an outpatient ERCP or a prolongation of a hospital stay following an ERCP. This diagnosis was associated with an increase in the serum lipase or amylase level of at least 3-fold greater than normal levels at approximately $24 \mathrm{~h}$ after the procedure [41].

We graded the severity of PEP as "mild" for those patients who required up to 3 additional hospital days, "moderate" for 
those staying between 4 and 10 days, and "severe" for those who spent more than 10 days or developed other serious complications. These complications include pancreatic necrosis, pancreatic pseudocyst formation and the need for percutaneous drainage or surgery.

High-risk ERCP was defined on the basis of prospectively validated patient- and procedure-related independent risk factors and according to the ASGE guidelines [26,40-42]. Patients were identified as high-risk if they met any of the following major criteria: clinical suspicion of SOD, a history of PEP, pancreatic sphincterotomy, precut sphincterotomy, difficult/failed cannulation ( $>8$ cannulation attempts or "difficult cannulation" statement in the procedure report), or pneumatic dilatation of an intact biliary sphincter. Patients were also considered as high-risk if they met 2 of the following minor criteria: female sex less than 50 years old, a history of recurrent pancreatitis ( $\geq 2$ episodes), limited pancreatogram ( 3 or more injections of contrast agent into the pancreatic duct with at least 1 injection to the tail of the pancreas), complete pancreatogram (excessive injection of contrast agent into the pancreatic duct resulting in opacification of pancreatic acini), or the acquisition of a cytological specimen from the pancreatic duct with the use of a brush.

A PDS was placed only to take advantage of the nonintentional presence of the guidewire into the pancreatic duct and based on the endoscopist's preference. There was no intentional cannulation of the pancreatic duct to place a stent, to decrease the risk of PEP.

\section{Outcomes}

The primary outcome of this study was to determine if RI reduces the incidence and severity of PEP in consecutive and low-risk ERCP.

\section{Statistical analysis}

Continuous variables were evaluated using the Student's $t$-test and categorical variables using the Fisher exact test. Patients who received RI were compared with those who did not receive RI. An analysis of clinical and procedural factors (Adverse events associated with ERCP, ASGE guideline 2017) associated with PEP was then conducted by performing univariate logistic regression analyses with development of PEP as the dependent variable and the following independent variables: age, sex, body mass index (BMI), procedure indication, bilirubin level, prior pancreatitis, prior PEP, cannulation of pancreatic duct with contrast, pancreatic or biliary sphincterotomy, difficult cannulation, brush/cytology, biopsy, stent placement, balloon dilation, and stone extraction. Any variable with $\mathrm{P}<0.1$ was included in the multivariate logistic regression model with the RI. Statistical analysis was carried out using JMP software (v10; SAS Institute Inc., Cary, NC).

\section{Results}

We evaluated 2238 patients who underwent ERCP and had adequate follow up (1055 in the RI group and 1183 in the control group). The average patient age was $60.4 \pm 18.7$ years; 1247 (56\%) patients were female and 991 (44\%) were male. The average BMI was $29 \pm 8.2 \mathrm{~kg} / \mathrm{m}^{2}$. Procedure details and patient characteristics are compared in Table 1.

\section{Study outcome}

Overall, PEP was diagnosed in 107 of the 2238 (4.5\%) patients who underwent ERCP, 48/1055 (4.5\%) in the RI group and $59 / 1183(5 \%)$ in the control group. There was no difference in the rate of bleeding between the 2 groups.

In the univariate analysis, the following factors were associated with PEP: females less than 40 years of age with a native papilla, contrast injection into the pancreatic duct, difficult cannulation, pancreatic sphincterotomy, failed PDS placement, native papilla, and a history of recurrent acute pancreatitis (Table 2).

In the multivariate model, contrast injection of the main pancreatic duct, difficult biliary cannulation, females less than 40 years of age, native papilla, pancreatic sphincterotomy, and failed PDS placement were associated with a higher incidence of PEP. RI reduced the incidence of PEP in consecutive patients by $55 \%(\mathrm{OR} 0.45,95 \% \mathrm{CI} 0.36-0.94 ; \mathrm{P}=0.03)$ and reduced the incidence of moderate/severe PEP by $47 \%$ (OR 0.53, 95\%CI 0.27-0.97; $\mathrm{P}=0.04$ ) (Table 3).

\section{RI impact on low-risk patients}

Of the 2238 patients, 364 (16\%) were considered at highrisk for PEP and 1874 (84\%) were at low-risk, according to the consensus definition in the Methods section. In the univariate model, PEP was associated with any contrast injection into the pancreatic duct, pancreatic sphincterotomy, biliary sphincterotomy, failed PDS, and female sex with native papilla. In the multivariate model, pancreatic sphincterotomy and biliary sphincterotomy were associated with a higher incidence of PEP. RI reduced the incidence of PEP in low-risk patients by $62 \%$ (OR $0.38,95 \%$ CI $0.19-0.74 ; \mathrm{P}=0.004$ ) (Table 4 ). RI reduced the incidence of moderate/severe PEP by $57 \%$ (OR 0.43, 95\%CI 0.18-0.10; $\mathrm{P}=0.049$ ).

\section{Propensity-matched group analysis of low-risk patients with native papilla}

To confirm our results, a propensity-matched analysis of patients grouped according to risk factors was performed: 437 patients in the control group were compared to 487 in the RI group. RI reduced the incidence of PEP by $61 \%$ (OR 0.39 , 95\%CI 0.18-0.8; $\mathrm{P}=0.009$ ) 
Table 1 Patient baseline characteristics for the control group and rectal indomethacin group $(\mathrm{n}=2238)$

\begin{tabular}{|c|c|c|c|}
\hline Risk factors $\mathrm{n} / \mathrm{N}(\%)$ & Control group (1183) & Rectal indomethacin group (1055) & P-value \\
\hline Native papilla & $502(42)$ & $563(53)$ & 0.01 \\
\hline Female sex & $676(57)$ & $571(46)$ & 0.15 \\
\hline Age & $61+18.7$ & $59 \pm 18.6$ & 0.07 \\
\hline BMI & $29.6+8.6$ & $28.4 \pm 7.8$ & 0.50 \\
\hline Smoking & $669(56.6)$ & $414(39)$ & 0.01 \\
\hline Ciprofloxacin pre-procedure & $419(35)$ & $717(68)$ & 0.01 \\
\hline Native papilla, female under 40 years with history of recurrent pancreatitis & $106(9)$ & $103(10)$ & 0.50 \\
\hline History of PEP & $27(2)$ & $24(2)$ & 0.99 \\
\hline History of acute pancreatitis & $217(18)$ & $253(24)$ & 0.01 \\
\hline History of recurrent pancreatitis & $41(4)$ & $66(6)$ & 0.02 \\
\hline Primary sclerosing cholangitis & 17 & 4 & 0.07 \\
\hline Race & & & 0.61 \\
\hline Caucasian (1385) & $732(62)$ & $653(62)$ & \\
\hline Black (542) & $215(18)$ & $327(31)$ & \\
\hline Hispanic (81) & $31(3)$ & $50(5)$ & \\
\hline Other (230) & 205 (19) & $25(3)$ & \\
\hline \multicolumn{4}{|l|}{ Indication } \\
\hline Benign biliary & $226(19)$ & $228(22)$ & \\
\hline Benign pancreatic lesion & $41(3.5)$ & $134(13)$ & \\
\hline Choledocholithiasis & $627(53)$ & $493(47)$ & \\
\hline Leak & $116(9.8)$ & $57(5)$ & \\
\hline Mass & $168(14.2)$ & $129(12)$ & \\
\hline Sphincter of Oddi dysfunction & $6(0.5)$ & $14(1.3)$ & \\
\hline Difficult cannulation & $172(15)$ & $67(7)$ & 0.03 \\
\hline Normal serum bilirubin & $694(59)$ & $468(65)$ & 0.03 \\
\hline Pancreatic sphincterotomy & $7(1)$ & $60(6)$ & 0.001 \\
\hline Cannulation of MPD & $229(20)$ & $430(41)$ & 0.001 \\
\hline Cannulation of MPD with wire only & $111(9)$ & $141(13)$ & 0.03 \\
\hline Contrast injection into pancreatic duct & $116(9.8)$ & $285(27)$ & 0.001 \\
\hline Limited pancreatogram & $45(4)$ & $99(9)$ & 0.001 \\
\hline Complete pancreatogram & $57(5)$ & $140(13)$ & 0.001 \\
\hline Biliary sphincterotomy & $502(42)$ & $563(53)$ & 0.001 \\
\hline Biliary duct/ampulla biopsy & $97(8)$ & $138(13)$ & 0.001 \\
\hline Biliary brush & $56(5)$ & $62(6)$ & 0.001 \\
\hline Biliary dilation & $235(20)$ & $299(28)$ & 0.001 \\
\hline Biliary stent insertion & $429(36)$ & $359(34)$ & 0.26 \\
\hline Pancreatic duct dilatation & $6(1)$ & $51(5)$ & 0.001 \\
\hline Pancreatic stent placement & $75(6)$ & $249(24)$ & 0.001 \\
\hline Failed PDS placement & $7(1)$ & $10(1)$ & 0.33 \\
\hline EUS FNA of the pancreas & $41(3)$ & $119(11)$ & 0.001 \\
\hline Previous PEP & $27(2)$ & $24(2)$ & 0.99 \\
\hline
\end{tabular}

BMI, body mass index; PEP, post-endoscopic retrograde cholangiopancreatography pancreatitis; MPD, main pancreatic duct; PDS, pancreatic duct stent; EUS, endoscopic ultrasound; FNA, fine-needle aspiration

\section{Discussion}

Our results showed that RI decreased the incidence of PEP by $42 \%$ and reduced the rate of moderate/severe PEP by $55 \%$ in consecutive patients. Analysis of only low-risk patients demonstrated that RI reduced the incidence of PEP by $62 \%$ and reduced the incidence of moderate/severe PEP by $57 \%$.
Our results are consistent with those of Thiruvengadam et al, who reported a reduction in the incidence of PEP by $65 \%$ and the incidence of moderate/severe PEP by $83 \%$. Previous trials showed no effect of RI in decreasing the incidence of PEP in low-risk patients [33-35]. The different outcomes could be due to the small sample sizes in these trials for detecting the differences in PEP, and the rarity of PEP in low-risk patients. 
Table 2 Incidence of post-endoscopic retrograde cholangiopancreatography pancreatitis according to risk factors in consecutive patients ( $\mathrm{n}=2238$ )

\begin{tabular}{|c|c|c|c|}
\hline Risk factors & PEP n (\%) & P-value & OR \\
\hline Female sex & $50 / 654(8)$ & 0.16 & $0.7(0.44-1.2)$ \\
\hline BMI & 0.32 & & \\
\hline Smoking & $36 / 571(6)$ & 0.55 & $0.9(0.54-1.4)$ \\
\hline Ciprofloxacin pre-procedure & $43 / 539(8)$ & 012 & $0.7(0.4-1.1)$ \\
\hline Oral NSAIDs & $26 / 500(5)$ & 0.37 & $1.2(0.8-1.9)$ \\
\hline Normal bilirubin & $42 / 532(8)$ & 0.15 & $1.4(0.88-2.2)$ \\
\hline History of PEP & $1 / 15(1)$ & 0.98 & $0.98(0.12-7.6)$ \\
\hline History of acute pancreatitis & $18 / 285(6)$ & 0.61 & $0.91(0.5-1.5)$ \\
\hline History of recurrent pancreatitis & $8 / 51(10)$ & 0.02 & $2.7(1.2-6.1)$ \\
\hline Primary sclerosing cholangitis & $1 / 7(5)$ & 0.48 & $2.3(0.28-19.5)$ \\
\hline Duodenal diverticula & $7 / 98(7)$ & 0.8 & $1.1(0.5-2.3)$ \\
\hline Difficult cannulation & $27 / 123(22)$ & 0.001 & $5.4(3.2-9.0)$ \\
\hline Cannulation of MPD & $42 / 337(12)$ & 0.001 & $3.1(1.9-4.9)$ \\
\hline Cannulation of MPD with wire only & $15 / 134(11)$ & 0.04 & $1.9(1.1-3.5)$ \\
\hline Limited pancreatogram & $14 / 63(22)$ & 0.001 & $4.6(2.4-8.8)$ \\
\hline Complete pancreatogram & $12 / 95(13)$ & 0.03 & $2.1(1.1-4.2)$ \\
\hline Biliary biopsy & $13 / 165(8)$ & 0.54 & $1.2(0.65-2.3)$ \\
\hline Biliary brush & $8 / 89(9)$ & 0.66 & $1.8(0.9-3.7)$ \\
\hline Biliary dilation & 29/541(5) & 0.07 & $0.07(0.4-1.0)$ \\
\hline Biliary stent insertion & $32 / 414(8)$ & 0.32 & $1.2(0.8-2.0)$ \\
\hline Pancreatic sphincterotomy & $12 / 67(18)$ & 0.001 & $5.1(1.7-6.6)$ \\
\hline Pancreatic duct dilatation & $3 / 31(10)$ & 0.53 & $1.5(0.4-5.0)$ \\
\hline PDS placement & $16 / 172(9)$ & 0.16 & $1.5(0.9-2.7)$ \\
\hline Rectal indomethacin & $34 / 629(5)$ & 0.04 & $0.6(0.4-0.9)$ \\
\hline Failed PDS placement & $8 / 17(47)$ & 0.001 & $53(10-260)$ \\
\hline Concomitant EUS FNA of the pancreas & $7 / 84(8)$ & 0.56 & $1.2(0.56-2.9)$ \\
\hline
\end{tabular}

BMI, body mass index; NSAIDs, non-steroidal anti-inflammatory drugs; PEP, post-endoscopic retrograde cholangiopancreatography pancreatitis; MPD, main pancreatic duct; PDS, pancreatic duct stent; EUS, endoscopic ultrasound; FNA, fine-needle aspiration

Table 3 Factors associated with post-endoscopic retrograde cholangiopancreatography pancreatitis in consecutive patients: multivariate analysis

\begin{tabular}{lcc}
\hline Factors & OR (95\%CI) & P-value \\
\hline $\begin{array}{l}\text { Administration of rectal } \\
\text { indomethacin }\end{array}$ & $0.45(0.25-0.79)$ & 0.04 \\
$\begin{array}{l}\text { Injection of main pancreatic duct } \\
\text { with contrast }\end{array}$ & $2.2(1.1-4.3)$ & 0.02 \\
$\begin{array}{l}\text { Difficult biliary cannulation } \\
\text { Pancreatic sphincterotomy }\end{array}$ & $4.2(2.4-0.4)$ & 0.001 \\
Failed PDS placement & $28(0.81-4.8)$ & 0.12 \\
Recurrent pancreatitis & $2.3(0.87-5.4)$ & 0.08 \\
\hline OR, odds ratio; CI, confidence interval: PDS, pancreatic duct stent &
\end{tabular}

There were some differences in patient- and procedurerelated risk factors. Compared to the control group, the RI
Table 4 Factors associated with post-endoscopic retrograde cholangiopancreatography pancreatitis in low-risk patients: multivariate analysis

\begin{tabular}{lcc} 
Factors & OR (95\%CI) & P-value \\
\hline $\begin{array}{l}\text { Administration of rectal } \\
\text { indomethacin }\end{array}$ & $0.38(0.19-0.7)$ & 0.004 \\
$\begin{array}{l}\text { Injection of main pancreatic duct } \\
\text { with contrast }\end{array}$ & $1.7(0.58-4.3)$ & 0.60 \\
Biliary sphincterotomy & $3.2(1.7-6.9)$ & 0.001 \\
Female with native papilla & $1.4(0.26-0.77)$ & 0.26 \\
Pancreatic sphincterotomy & $6.7(1.4-28.8)$ & 0.02 \\
Failed PDS placement & $8.4(0.31-84.8)$ & 0.3 \\
\hline OR, odds ratio; CI, confidence interval; PDS, pancreatic duct stent &
\end{tabular}

group had a slightly higher percentage of patient-related risk factors: native papilla (53\% vs. $42 \%$ ), history of recurrent 
pancreatitis ( $4 \%$ vs. $2 \%$ ), and SOD (14 vs. 6 patients). Likewise, the RI group had slightly higher prevalence of procedurerelated risk factors: pancreatic sphincterotomy (6\% vs. $1 \%)$, main pancreatic duct cannulation ( $41 \%$ vs. $20 \%)$, and contrast injection into the pancreatic duct ( $27 \%$ vs. 9.8$)$. The RI group had a higher incidence of PDS placement (24\% vs. $6 \%)$. The multivariate analysis model that combined all possible patient- and procedure-related risk factors demonstrated that RI truly reduced the rate of PEP. Given the higher prevalence of risk factors in the RI group, we further confirmed our multivariate model with a propensity-matched group of lowrisk patients with native papilla. Likewise, RI reduced the incidence of PEP by $61 \%$ (OR 0.39, 95\%CI 0.18-0.8; $\mathrm{P}=0.009$ ).

In our study, we found that females less than 40 years of age with a native papilla, contrast injection of the pancreatic duct, difficult cannulation, pancreatic sphincterotomy, failed PDS placement, native papilla, and a history of recurrent pancreatitis were associated with PEP. This is consistent with previous reports [6].

In our study, $83 \%$ of the patients considered low-risk for PEP. Our overall reported rate of PEP was $4.5 \%$, close to the reported rate of $4.2 \%$ in a large systemic review by Andriulli et al [4]. However, it is worth mentioning that the positive effect of RI in low-risk patients could be explained by the relatively high incidence of PEP in both our study and that of Thiruvengadam et al (4.5\% and $7.53 \%$, respectively). Patients were considered low-risk for ERCP if they did not meet the high-risk criteria defined in prospectively validated trials [26,40-42]. Procedure- and patient-independent risk factors for PEP were studied extensively, but did not show potential for predicting every case of PEP. Occasionally, meeting a single minor criterion for high-risk ERCP could markedly increase the risk of PEP without fulfilling the high-risk ERCP criteria (1 major or 2 minor criteria); such criteria included any injection into the pancreatic duct, and female sex with native papilla having wire cannulation into the pancreatic duct. Thus, we performed an analysis of consecutive patients as well as only those at low risk for ERCP, to confirm that the effect on PEP applies to any patients undergoing ERCP, regardless of their risk factors.

The mechanism leading to PEP has not been fully established. It has been suggested that local injury to the papilla from instrumentation, sphincterotomy, or forceful and repetitive injection of contrast causes papillary edema or spasm. This is thought to result in ductal hypertension followed by reduced pancreatic duct drainage. The poor drainage initiates an inflammatory cascade, promoting intraluminal activation of proteolytic enzymes and autodigestion of the pancreas. Significant release of cytokines (interleukins 1, 6 and 8) results in a systemic inflammatory response with multiorgan involvement $[8,43]$.

PDS maintains pancreatic drainage to the ampulla through the pancreatic duct after ERCP, without providing prophylaxis for other proposed mechanisms of PEP, including chemical, allergic, enzymatic and infectious mechanisms [44]. Indomethacin, an NSAID, is a potent inhibitor of cyclooxygenase, neutrophilendothelial interactions and phospholipase A2. Phospholipase A2 regulates the pro-inflammatory mediators, including arachidonic acid products and platelet-activating factors. This inhibition is thought to be key in aborting the early steps in the inflammatory cascade process and preventing PEP $[45,46]$.

Thiruvengadam et al reported the maximal reduction of PEP when using RI in patients with malignant obstruction compared to the control group (2.3\% vs. $7.5 \%)$ [34]. We did not see a significant reduction in PEP in patients with a malignant obstruction compared to the control group. This may have been due to the overall low incidence of PEP in our malignant obstruction patients $(2.7 \%)$. It is worth noting that more patients in the RI group received prophylactic ciprofloxacin before the procedure compared to the control group. Our subgroup analysis did not show any impact of ciprofloxacin on the incidence of PEP.

One of the main strengths of our study was the large sample size with adequate power to detect the impact of RI on preventing PEP in a primarily low-risk endoscopy unit. This mixed study population should mirror and be applicable to many ERCP practices. In addition, the unique geographic location of our hospital as the only tertiary referral center serving 29 counties helps to ensure adequate follow up of any possible ERCP complications. Nevertheless, our study has several limitations. First, its retrospective nature, comparing 2 heterogeneous groups, is subjective to confounder bias for the baseline patient risk of PEP. We tried to control for this limitation by collecting all possible risk factors and by performing univariate and multivariate analyses to explore all potential confounders. Second, there was a difference in time period and individual endoscopists between the RI group and control group. We did not find any differences in the incidence of PEP in relation to the ERCP year or the endoscopists. Third, large-volume hydration as a prophylaxis for PEP was not adopted during the study period and could not be reliably examined as a confounder. Finally, the number of PDS placements in the study population was small and lacked uniform criteria.

In conclusion, RI reduced the incidence and severity of PEP in consecutive and low-risk patients. The combination of RI with PDS may not offer any additional benefit to RI alone. Given the high safety profile and the low cost, RI should be considered for every patient undergoing ERCP.

\section{Summary Box}

\section{What is already known:}

- Post-endoscopicretrogradecholangiopancreatography (ERCP) pancreatitis (PEP) is the most frequent major complication of ERCP

- Rectal indomethacin decreases the risk of PEP in high-risk patients

\section{What the new finding is:}

- Rectal indomethacin reduces the risk of PEP in low-risk patients 


\section{References}

1. Freeman ML, Guda NM. Prevention of post-ERCP pancreatitis: a comprehensive review. Gastrointest Endosc 2004;59:845-864.

2. Kochar B, Akshintala VS, Afghani E, et al. Incidence, severity, and mortality of post-ERCP pancreatitis: a systematic review by using randomized, controlled trials. Gastrointest Endosc 2015;81:143-149

3. Wang AY, Strand DS, Shami VM. Prevention of post-endoscopic retrograde cholangiopancreatography pancreatitis: medications and techniques. Clin Gastroenterol Hepatol 2016;14:1521-1532.

4. Andriulli A, Loperfido S, Napolitano G, et al. Incidence rates of post-ERCP complications: a systematic survey of prospective studies. Am J Gastroenterol 2007;102:1781-1788.

5. Freeman ML, Nelson DB, Sherman S, et al. Complications of endoscopic biliary sphincterotomy. N Engl J Med 1996;335:909-918.

6. Freeman ML, DiSario JA, Nelson DB, et al. Risk factors for postERCP pancreatitis: a prospective, multicenter study. Gastrointest Endosc 2001;54:425-434.

7. Sherman S, Lehman GA. ERCP- and endoscopic sphincterotomyinduced pancreatitis. Pancreas 1991;6:350-367.

8. Sherman S, Ruffolo TA, Hawes RH, Lehman GA. Complications of endoscopic sphincterotomy. A prospective series with emphasis on the increased risk associated with sphincter of Oddi dysfunction and nondilated bile ducts. Gastroenterology 1991;101:1068-1075.

9. Cotton PB, Lehman G, Vennes J, et al. Endoscopic sphincterotomy complications and their management: an attempt at consensus. Gastrointest Endosc 1991;37:383-393.

10. Freeman ML. Role of pancreatic stents in prevention of post-ERCP pancreatitis. JOP 2004;5:322-327.

11. Cha SW, Leung WD, Lehman GA, et al. Does leaving a main pancreatic duct stent in place reduce the incidence of precut biliary sphincterotomy-associated pancreatitis? A randomized, prospective study. Gastrointest Endosc 2013;77:209-216.

12. Sofuni A, Maguchi H, Mukai T, et al. Endoscopic pancreatic duct stents reduce the incidence of post-endoscopic retrograde cholangiopancreatography pancreatitis in high-risk patients. Clin Gastroenterol Hepatol 2011;9:851-858; quiz e110.

13. Tarnasky PR, Palesch YY, Cunningham JT, Mauldin PD, Cotton PB, Hawes RH. Pancreatic stenting prevents pancreatitis after biliary sphincterotomy in patients with sphincter of Oddi dysfunction. Gastroenterology 1998;115:1518-1524.

14. Saad AM, Fogel EL, McHenry L, et al. Pancreatic duct stent placement prevents post-ERCP pancreatitis in patients with suspected sphincter of Oddi dysfunction but normal manometry results. Gastrointest Endosc 2008;67:255-261.

15. Mazaki T, Masuda H, Takayama T. Prophylactic pancreatic stent placement and post-ERCP pancreatitis: a systematic review and meta-analysis. Endoscopy 2010;42:842-853.

16. Smithline A, Silverman W, Rogers D, et al. Effect of prophylactic main pancreatic duct stenting on the incidence of biliary endoscopic sphincterotomy-induced pancreatitis in high-risk patients. Gastrointest Endosc 1993;39:652-657.

17. Fazel A, Quadri A, Catalano MF, Meyerson SM, Geenen JE. Does a pancreatic duct stent prevent post-ERCP pancreatitis? A prospective randomized study. Gastrointest Endosc 2003;57:291-294.

18. Lee TH, Moon JH, Choi HJ, et al. Prophylactic temporary 3F pancreatic duct stent to prevent post-ERCP pancreatitis in patients with a difficult biliary cannulation: a multicenter, prospective, randomized study. Gastrointest Endosc 2012;76:578-585.

19. Harewood GC, Pochron NL, Gostout CJ. Prospective, randomized, controlled trial of prophylactic pancreatic stent placement for endoscopic snare excision of the duodenal ampulla. Gastrointest Endosc 2005;62:367-370.
20. Choudhary A, Bechtold ML, Arif M, et al. Pancreatic stents for prophylaxis against post-ERCP pancreatitis: a meta-analysis and systematic review. Gastrointest Endosc 2011;73:275-282.

21. Andriulli A, Forlano R, Napolitano G, et al. Pancreatic duct stents in the prophylaxis of pancreatic damage after endoscopic retrograde cholangiopancreatography: a systematic analysis of benefits and associated risks. Digestion 2007;75:156-163.

22. Singh P, Das A, Isenberg G, et al. Does prophylactic pancreatic stent placement reduce the risk of post-ERCP acute pancreatitis? A metaanalysis of controlled trials. Gastrointest Endosc 2004;60:544-550.

23. Elton E, Howell DA, Parsons WG, Qaseem T, Hanson BL. Endoscopic pancreatic sphincterotomy: indications, outcome, and a safe stentless technique. Gastrointest Endosc 1998;47:240-249.

24. Freeman ML, Overby C, Qi D. Pancreatic stent insertion: consequences of failure and results of a modified technique to maximize success. Gastrointest Endosc 2004;59:8-14.

25. Bakman YG, Safdar K, Freeman ML. Significant clinical implications of prophylactic pancreatic stent placement in previously normal pancreatic ducts. Endoscopy 2009;41:1095-1098.

26. Elmunzer BJ, Scheiman JM, Lehman GA, et al; U.S. Cooperative for Outcomes Research in Endoscopy (USCORE). A randomized trial of rectal indomethacin to prevent post-ERCP pancreatitis. N Engl J Med 2012;366:1414-1422.

27. Baron TH, Abu Dayyeh BK, Abu Dayye BK, Zinsmeister AR. Rectal indomethacin to prevent post-ERCP pancreatitis. $N$ Engl J Med 2012;367:277-278; author reply 278-9.

28. Ding X, Chen M, Huang S, Zhang S, Zou X. Nonsteroidal antiinflammatory drugs for prevention of post-ERCP pancreatitis: a meta-analysis. Gastrointest Endosc 2012;76:1152-1159.

29. Yuhara H, Ogawa M, Kawaguchi Y, Igarashi M, Shimosegawa T, Mine T. Pharmacologic prophylaxis of post-endoscopic retrograde cholangiopancreatography pancreatitis: protease inhibitors and NSAIDs in a meta-analysis. J Gastroenterol 2014;49:388-399.

30. Dumonceau JM, Andriulli A, Elmunzer BJ, et al; European Society of Gastrointestinal Endoscopy. Prophylaxis of post-ERCP pancreatitis: European Society of Gastrointestinal Endoscopy (ESGE) Guideline - updated June 2014. Endoscopy 2014;46:799-815.

31. Isaji S, Takada T, Mayumi T, et al. Revised Japanese guidelines for the management of acute pancreatitis 2015: revised concepts and updated points. J Hepatobiliary Pancreat Sci 2015;22:433-445.

32. Thiruvengadam NR, Forde KA, Ma GK, et al. Rectal indomethacin reduces pancreatitis in high- and low-risk patients undergoing endoscopic retrograde cholangiopancreatography. Gastroenterology 2016;151:288-297.

33. Levenick JM, Gordon SR, Fadden LL, et al. Rectal indomethacin does not prevent post-ERCP pancreatitis in consecutive patients. Gastroenterology 2016;150:911-917; quiz e19.

34. Döbrönte Z, Szepes Z, Izbéki F, et al. Is rectal indomethacin effective in preventing of post-endoscopic retrograde cholangiopancreatography pancreatitis? World J Gastroenterol 2014;20:10151-10157.

35. Lua GW, Muthukaruppan R, Menon J. Can rectal diclofenac prevent post endoscopic retrograde cholangiopancreatography pancreatitis? Dig Dis Sci 2015;60:3118-3123.

36. Feng Y, Navaneethan U, Zhu X, et al. Prophylactic rectal indomethacin may be ineffective for preventing post-endoscopic retrograde cholangiopancreatography pancreatitis in general patients: A meta-analysis. Dig Endosc 2017;29:272-280.

37. Inamdar S, Han D, Passi M, Sejpal DV, Trindade AJ. Rectal indomethacin is protective against post-ERCP pancreatitis in highrisk patients but not average-risk patients: a systematic review and meta-analysis. Gastrointest Endosc 2017;85:67-75.

38. Rainio M, Lindström $\mathrm{O}$, Udd $\mathrm{M}$, Louhimo J, Kylänpää L. Diclofenac does not reduce the risk of post-endoscopic retrograde cholangiopancreatography pancreatitis in low-risk units. J Gastrointest Surg 2017;21:1270-1277. 
39. Chandrasekhara V, Khashab MA, Muthusamy VR, et al; ASGE Standards of Practice Committee. Adverse events associated with ERCP. Gastrointest Endosc 2017;85:32-47.

40. Andrade-Dávila VF, Chávez-Tostado M, Dávalos-Cobián C, et al. Rectal indomethacin versus placebo to reduce the incidence of pancreatitis after endoscopic retrograde cholangiopancreatography: results of a controlled clinical trial. BMC Gastroenterol 2015;15:85.

41. Freeman ML. Pancreatic stents for prevention of post-endoscopic retrograde cholangiopancreatography pancreatitis. Clin Gastroenterol Hepatol 2007;5:1354-1365.

42. Rustagi T, Jamidar PA. Endoscopic retrograde cholangiopancreatography (ERCP)-related adverse events: postERCP pancreatitis. Gastrointest Endosc Clin N Am 2015;25:107-121.
43. Pezzilli R, Romboli E, Campana D, Corinaldesi R. Mechanisms involved in the onset of post-ERCP pancreatitis. JOP 2002;3:162168.

44. Cotton PB, Garrow DA, Gallagher J, Romagnuolo J. Risk factors for complications after ERCP: a multivariate analysis of 11,497 procedures over 12 years. Gastrointest Endosc 2009;70:80-88.

45. Gross V, Leser HG, Heinisch A, Schölmerich J. Inflammatory mediators and cytokines-new aspects of the pathophysiology and assessment of severity of acute pancreatitis? Hepatogastroenterology 1993;40:522-530.

46. Mäkelä A, Kuusi T, Schröder T. Inhibition of serum phospholipase-A2 in acute pancreatitis by pharmacological agents in vitro. Scand J Clin Lab Invest 1997;57:401-407. 